\title{
Incidence and risk of chondrolysis in Denmark: A nationwide population-based study
}

\section{Christian F Christiansen Sandra K Thygesen Lars Pedersen}

Department of Clinical Epidemiology, Aarhus University Hospital, Aarhus, Denmark
Correspondence: Christian F Christiansen Epidemiology, Aarhus University Hospital, Olof Palmes Alle 43-45, DK-8200

Aarhus C, Denmark

$\mathrm{Tel}+4589424800$

Fax +4589424801

Email cc@dce.au.dk
This article was published in the following Dove Press journal:

Clinical Epidemiology

8 May 2010

Number of times this article has been viewed

Background: Chondrolysis is a rare disease with destruction of cartilage of joints. Incidence and risk factors have not been studied in a formal epidemiologic population-based setting.

Methods: We used the Danish National Registry of Patients (NRP) covering all Danish hospitals to identify all cases of chondrolysis from 1994 to 2008. Incidence rates were estimated using the general population as the denominator. For each chondrolysis patient, 10 age-matched population controls were sampled for a case-control analysis. For cases and controls, we ascertained in the NRP history of diabetes, rheumatoid arthritis, orthopedic surgery, including surgery of shoulder and upper arm, injury to shoulder girdle or upper arm, and treatment with pain pump. We determined the prevalence of these risk factors in cases and controls, and computed odds ratios (OR).

Results: We identified 43 patients with chondrolysis in the 15 -year study period. The incidence rate was 5.5 per 10,000,000 person-years. Diabetes was more prevalent in chondrolysis cases, compared with the 430 controls ( $\mathrm{OR}=6.7 ; 95 \%$ confidence intervals $[\mathrm{CI}]: 1.1-39.9)$. Orthopedic surgery was also associated with an increased risk of chondrolysis $(\mathrm{OR}=28.8,95 \% \mathrm{CI}$ : 11.0-75.6), while previous injury was not ( $\mathrm{OR}=0.8 ; 95 \% \mathrm{CI}$ : $0.1-5.9)$.

Conclusion: Chondrolysis was rarely diagnosed in Denmark. Diabetes and orthopedic surgery may be risk factors.

Keywords: epidemiology, surgery, incidence, risk factors

\section{Introduction}

Chondrolysis is a rare disease characterized by destruction of cartilage of joints such as hip, knee, ankle, or shoulder. ${ }^{1}$ The relevant literature is virtually restricted to case reports and case series. ${ }^{1}$ Chondrolysis has been reported among adolescent females after slipped capital femoral epiphysis. ${ }^{2}$ Other suggested risk factors include trauma, infections, and prolonged immobilization. ${ }^{1}$

Chondrolysis of the shoulder (glenohumeral chondrolysis) has been reported most frequently among young men. ${ }^{3}$ Recently, a case series described glenohumeral chondrolysis after shoulder arthroscopy, ${ }^{4}$ in two and eight cases after arthroscopic thermal capsuorrhaphy, ${ }^{5,6}$ and in two patients after color tests using gentian violet in two cases after a color test. ${ }^{7}$ Use of intra-articular pain pump infusing bupivacaine has also been associated with glenohumeral chondrolysis ${ }^{8}$ in case series including 12 cases $^{9}$ and 23 cases, ${ }^{10}$ and in one case with bilateral shoulder arthroscopy in which chondrolysis developed at the side of pain catheter. ${ }^{11}$

Incidence and risk factors for chondrolysis have not been assessed in a populationbased setting in a formal epidemiological study. Such data could help us to understand and potentially prevent this rare, but serious, disease. 
We conducted a population-based case-control study to estimate the incidence of chondrolysis, and explore potential risk factors.

\section{Methods}

We conducted this population-based case-control study in Denmark (population 5.4 million). The Danish National Health Service provides free tax-funded medical care for all Danish residents. The unique civil registration number assigned to every Danish citizen enabled electronic linkage of several medical databases. ${ }^{12}$ The study was approved by the Central Denmark Region on behalf of the Danish Data Protection Agency and by the Aarhus University Registry Board.

\section{Cases with chondrolysis}

We identified all cases of chondrolysis recorded during the 15-year period between January 1, 1994 and December 31, 2008 in the Danish NRP. ${ }^{13}$ The NRP has tracked all discharges from all somatic hospitals since 1977, including, since 1995, emergency room and outpatient clinic visits. Each record contains variables for patients' civil registration numbers, dates of admission and discharge, surgical procedures, treatments, and up to 20 diagnoses, coded by physicians according to the International Classification of Diseases (ICD) (8th edition until the end of 1993, 10 th edition thereafter). The ICD-10 code used to identify cases of chondrolysis was M94.3. In order to estimate the validity of the NRP diagnoses, we reviewed medical records of patients in Northern Jutland (population 0.6 million). ${ }^{14-16}$

\section{Population controls}

From the Danish Civil Registration System (CRS), ${ }^{12}$ we selected 10 age-matched population controls for each chondrolysis case. Controls were sampled using risk-set sampling from among the Danes who were alive on the date an index chondrolysis case was diagnosed (the index date). The CRS, which was established in 1968, is updated daily and contains data on civil registration number, residence, migration, vital status (dead or alive), and date of death for all Danish residents.

\section{Potential risk factors}

From the NRP, we obtained data on any history (until the index date) of orthopedic surgery or surgery of the shoulder or upper limb which has been recorded since 1989, data on any history of injuries to the upper arm or shoulder girdle for up to 20 years before the index date (the diagnostic codes are provided in the Appendix), and data on history of diabetes or rheumatoid arthritis for up to 20 years before index date. We also included NRP records of pain pump treatment, which has been recorded since 1999 . Because the data quality of this code is unknown, we selected for medical record review patients registered with pain pump treatment at one of the university hospitals.

\section{Statistical analyses}

The incidence of chondrolysis was computed in 10-year age groups. Incidence rates were estimated using the general population as a denominator, using the corresponding age group listed in the official reports by Statistics Denmark. ${ }^{17}$

The prevalence of risk factors was described for cases and controls. Unadjusted odds ratios (ORs) were computed by conditional logistic regression for potential risk factors comparing chondrolysis cases with age-matched controls. Using risk-set sampling for control selection renders the OR interpretable as an estimate of the corresponding rate ratio (RR).

Statistical analyses were performed with SAS software (version 9.1; SAS Institute, Cary, NC).

\section{Results}

We identified 43 patients diagnosed with chondrolysis in the study period; $32(74.4 \%)$ were aged $20-49$ years, and $22(51.2 \%)$ were males (Table 1$)$. Twenty patients were diagnosed in 1994-1999 and 23 were diagnosed in 2000-2008.

The incidence rate (IR) of chondrolysis in the Danish population was 5.5 per $10,000,000$ person-years, and it was the highest in persons aged $40-49$ years (IR $=11.9$ per 10,000,000 person-years) (Table 2).

Two $(4.7 \%)$ of the 43 chondrolysis cases had a history of diabetes compared with $3(0.7 \%)$ of the 430 population controls, corresponding to an OR of 6.7 (95\% confidence intervals [CI]: 1.1-39.9). A history of rheumatoid arthritis was recorded for one chondrolysis case and one control $(\mathrm{OR}=$ 10.0; 95\% CI: 0.6-159.9) (Tables 1 and 3). One chondrolysis case $(2.3 \%)$ and $13(3.0 \%)$ controls had a history of upper arm and shoulder girdle $(\mathrm{OR}=0.8 ; 95 \% \mathrm{CI}$ : 0.1-5.9). A history of orthopedic procedure was recorded in a majority of the chondrolysis patients $(74.4 \%)$, but was less common among the controls (13.5\%), corresponding to an OR of 28.8 (95\% CI: 11.0-75.6). Likewise, cases were more likely than controls to have undergone a surgery of shoulder and upper arm (7.0\% vs 3.5\%; OR = 2.1, 95\% CI: 0.6-7.8). No cases or controls were coded with pain pump treatment. 
Table I Characteristics of chondrolysis cases and population controls

\begin{tabular}{|c|c|c|c|c|}
\hline & \multicolumn{2}{|c|}{$\begin{array}{l}\text { Chondrolysis } \\
\text { cases }(n=43)\end{array}$} & \multicolumn{2}{|c|}{$\begin{array}{l}\text { Population } \\
\text { controls } \\
(n=430)\end{array}$} \\
\hline & $\mathbf{n}$ & $\%$ & $\mathbf{n}$ & $\%$ \\
\hline \multicolumn{5}{|l|}{ Age group, years } \\
\hline $10-19$ & 2 & 4.7 & 20 & 4.7 \\
\hline $20-29$ & 10 & 23.3 & 100 & 23.3 \\
\hline $30-39$ & 8 & 18.6 & 80 & 18.6 \\
\hline $40-49$ & 14 & 32.6 & 140 & 32.6 \\
\hline $50-59$ & 6 & 14.0 & 60 & 14.0 \\
\hline $60-69$ & 0 & 0.0 & 0 & 0.0 \\
\hline 70-79 & 1 & 2.3 & 10 & 2.3 \\
\hline $80-89$ & 2 & 4.7 & 20 & 4.7 \\
\hline \multicolumn{5}{|l|}{ Sex } \\
\hline Female & 21 & 48.8 & 223 & 51.9 \\
\hline Male & 22 & 51.2 & 207 & 48.1 \\
\hline Diabetes & 2 & 4.7 & 3 & 0.7 \\
\hline Rheumatoid arthritis & 1 & 2.3 & 1 & 0.2 \\
\hline $\begin{array}{l}\text { Injury involving the } \\
\text { upper arm and } \\
\text { shoulder girdle }\end{array}$ & 1 & 2.3 & 13 & 3.0 \\
\hline $\begin{array}{l}\text { A history of orthopedic } \\
\text { surgery }\end{array}$ & 32 & 74.4 & 58 & 13.5 \\
\hline $\begin{array}{l}\text { A history of surgery of } \\
\text { shoulder or upper arm }\end{array}$ & 3 & 7.0 & 15 & 3.5 \\
\hline Pain pump treatment & 0 & 0.0 & 0 & 0.0 \\
\hline
\end{tabular}

\section{Medical record review}

Five patients with chondrolysis in the Northern Jutland were identified in the NRP, but only four medical records were available and reviewed. All four medical record had described cartilage lesion, but there we no specific details. The positive predictive value (PPV) of the recorded diagnosis would be 100\% (97.5\% one-sided CI: 48\%-100\%) assuming the missing record had a confirmed cartilage lesion and PPV would be $80 \%$ (95\% CI: 28\%-99\%), if missing record were not confirmed.

Table 2 Incidence of a hospital diagnosis of chondrolysis in the Danish population

\begin{tabular}{llll}
\hline & $\begin{array}{l}\text { Hospital } \\
\text { diagnosis of } \\
\text { chondrolysis } \\
\text { I994-2008 (N) }\end{array}$ & $\begin{array}{l}\text { Danish } \\
\text { population } \\
\text { on January I, } \\
\text { I994 }\end{array}$ & $\begin{array}{l}\text { Incidence rates } \\
\text { per I0,000,000 } \\
\text { person-years }\end{array}$ \\
\hline Age group & & & \\
10-19 years & 2 & 619,998 & 2.15 \\
20-29 years & 10 & 791,046 & 8.43 \\
30-39 years & 8 & 759,894 & 7.02 \\
40-49 years & 14 & 785,348 & 11.88 \\
$50-59$ years & 6 & 592,627 & 6.75 \\
$60-69$ years & 0 & 467,229 & 0.00 \\
$70-79$ years & 1 & 369,445 & 1.80 \\
$80-89$ years & 2 & 176,927 & 7.54 \\
\hline
\end{tabular}

Table 3 Odds ratios (OR) of chondrolysis in patients with risk factors compared with those without this risk factor

\begin{tabular}{ll}
\hline & OR (95\% CI) \\
\hline Male sex & $\mathrm{I} . \mathrm{I}(0.6-2 . \mathrm{I})$ \\
History of diabetes & $6.7(\mathrm{I} . \mathrm{I}-39.9)$ \\
History of rheumatoid arthritis & $\mathrm{I} 0.0(0.6-\mathrm{I} 59.9)$ \\
History of injury involving the upper & $0.8(0.1-5.9)$ \\
arm and shoulder girdle & \\
History of any orthopedic surgery & $28.8(\mathrm{II} .0-75.6)$ \\
History of surgery of shoulder or upper arm & $2.1(0.6-7.8)$ \\
\hline Abbreviation: $\mathrm{Cl}$, confidence interval. &
\end{tabular}

From the NRP, we identified all 46 patients with a pain pump code since 1999 at one university hospital. The medical record contained notes of pain pump coding for 23 of the patients. An additional four patients had a note in the medical record on the date of pain pump treatment, but this treatment was not described in the text. The remaining 19 patients did not have a description of the pump in the surgical record, but some of these may most likely have been treated with pain pump by anesthesiologists, who had recorded it on separate observation sheets that were available in the surgical record. The PPV of pain pump treatment was thus $50 \%(95 \%$ CI: $35 \%-65 \%)$ or $91 \%(95 \%$ CI: 79\%-98\%), depending on whether patients without a note in the medical record actually underwent pain pump treatment.

\section{Discussion}

This is the first study that addressed the basic epidemiology of chondrolysis in a population-based setting. A diagnosis of chondrolysis in Denmark was rare. Most patients were aged 20-49 years, with nearly equal proportions of males and females. A history of orthopedic surgery or diabetes was associated with an increased risk of chondrolysis.

Our study extends previous reports of chondrolysis after orthopedic surgery, including shoulder surgery., ${ }^{2,4,6,9,11,18}$ In contrast to previous reports, we found the highest rate of chondrolysis in middle-aged women and men. The finding regarding diabetes was surprising.

This study had the strength of a population-based design within a free tax-supported health care system reducing selection and referral bias, but there were several limitations. Chondrolysis is not a clinical well-defined disease and it is most likely that it is under-recorded in the hospital registry particularly in milder cases; therefore our incidence estimates are most likely conservative. Misclassification of risk factors is most likely nondifferential as these data are obtained independently on outcome and may bias our estimates towards unity. 
Because no code for chondrolysis existed in the ICD-8 used in Denmark before 1994, prevalent cases could not be excluded from our sample. Our case series may therefore be a mixture of incident and prevalent cases, which may explain a slightly higher annual number of cases in 1994-1999 compared with 2000-2008. Still, the difference in these time periods is small and unlikely to explain away the observation that chondrolysis patients in our study were older compared with previous reports.

NRP data on diabetes hospitalization is known to be valid, however, we may only have included the most severe cases of diabetes as patients with milder type 2 diabetes may be treated by general practitioner only and would therefore not appear in the registry. ${ }^{19,20}$ Surgical procedures are registered in the NRP with high validity. ${ }^{21}$ The completeness of registration of pain pump treatment is unknown; the medical record review showed that a majority of the patients with notes at time of treatment actually had pain pump treatment. We had no data on localization of chondrolysis, which may explain the lower association between chrondolysis and surgery of shoulder and upper arm compared with any orthopedic surgery.

In conclusion, chondrolysis was rarely diagnosed in Denmark. Our data suggest that diabetes and orthopedic surgery may be risk factors.

\section{Disclosures}

The authors report no conflicts of interest in this work.

\section{References}

1. Yarbrough R, Gross R. Chondrolysis: an update. J Pediatr Orthop. 2005;25(5):702-704.

2. Ingram AJ, Clarke MS, Clarke CS Jr, Marshall WR. Chondrolysis complicating slipped capital femoral epiphysis. Clin Orthop Relat Res. 1982;(165):99-109.

3. Solomon DJ, Navaie M, Stedje-Larsen ET, Smith JC, Provencher MT. Glenohumeral chondrolysis after arthroscopy: a systematic review of potential contributors and causal pathways. Arthroscopy. 2009;25(11):1329-1342.

4. Petty DH, Jazrawi LM, Estrada LS, Andrews JR. Glenohumeral chondrolysis after shoulder arthroscopy: case reports and review of the literature. Am J Sports Med. 2004;32(2):509-515.

5. Levine WN, Clark AM Jr, D'Alessandro DF, Yamaguchi K. Chondrolysis following arthroscopic thermal capsulorrhaphy to treat shoulder instability. A report of two cases. J Bone Joint Surg Am. 2005;87(3):616-621.
6. Good CR, Shindle MK, Kelly BT, Wanich T, Warren RF. Glenohumeral chondrolysis after shoulder arthroscopy with thermal capsulorrhaphy. Arthroscopy. 2007;23(7):797-5.

7. Shibata Y, Midorikawa K, Koga T, Honjo N, Naito M. Chondrolysis of the glenohumeral joint following a color test using gentian violet. Int Orthop. 2001;25(6):401-403.

8. Busfield BT, Romero DM. Pain pump use after shoulder arthroscopy as a cause of glenohumeral chondrolysis. Arthroscopy. 2009;25(6):647-652.

9. Hansen BP, Beck CL, Beck EP, Townsley RW. Postarthroscopic glenohumeral chondrolysis. Am J Sports Med. 2007;35(10):1628-1634.

10. Bailie DS, Ellenbecker TS. Severe chondrolysis after shoulder arthroscopy: a case series. $J$ Shoulder Elbow Surg. 2009;18(5):742-747.

11. Saltzman M, Mercer D, Bertelsen A, Warme W, Matsen F. Postsurgical chondrolysis of the shoulder. Orthopedics. 2009;32(3):215.

12. Frank L. Epidemiology. When an entire country is a cohort. Science. 2000;287(5462):2398-2399.

13. Andersen TF, Madsen M, Jorgensen J, Mellemkjoer L, Olsen JH. The Danish National Hospital Register. A valuable source of data for modern health sciences. Dan Med Bull. 1999;46(3):263-268.

14. Sorensen HT, Skriver MV, Friis S, McLaughlin JK, Blot WJ, Baron JA. Use of antibiotics and risk of breast cancer: a population-based casecontrol study. Br J Cancer. 2005;92(3):594-596.

15. Tetsche MS, Norgaard M, Skriver MV, Andersen ES, Lash TL, Sorensen HT. Accuracy of ovarian cancer ICD-10 diagnosis in a Danish population-based hospital discharge registry. Eur J Gynaecol Oncol. 2005;26(3):266-270.

16. Norgaard M, Skriver MV, Gregersen H, Pedersen G, Schonheyder HC, Sorensen HT. The data quality of hematological malignancy ICD-10 diagnoses in a population-based hospital discharge registry. Eur $J$ Cancer Prev. 2005;14(3):201-206.

17. Statbank Denmark [homepage on the Internet]. Copenhagen: Denmark Statistic [updated 2010 April 2]. Available from: http://www.statbank. dk. Acessed 2010 January 28.

18. Tamai K, Higashi A, Cho S, Yamaguchi T. Chondrolysis of the shoulder following a "color test" - assisted rotator cuff repair - a report of two cases. Acta Orthop Scand. 1997;68(4):401-402.

19. Nielsen GL, Sorensen HT, Pedersen AB, Sabroe S. Analyses of data quality in registries concerning diabetes mellitus - a comparison between a population based hospital discharge and an insulin prescription registry. J Med Syst. 1996;20(1):1-10.

20. Thygesen SK, Christiansen CF, Lash TL, Christensen S, Sorensen HT. The predictive value of ICD-10 diagnoses in population-based hospital registries used to assess Charlson Comorbidity Index. Pharmacoepidemiology and Drug Safety. Pharmacoepidemiology and Drug Safety 18, S189. 2009.

21. Kjaergaard J, Clemmensen IH, Storm HH. Validity and completeness of registration of surgically treated malignant gynaecological diseases in the Danish National Hospital Registry. J Epidemiol Biostat. 2001;6(5):387-392. 


\section{Appendix}

Codes for diagnoses, treatments, and surgery

History up to 20 years prior to index date of:

Diabetes mellitus

ICD-8: 249-250

ICD-10: E10-E14, O24 (except O24.4), H36.0

\section{Rheumatoid arthritis}

ICD-8: 712

ICD-10: M05, M06, M08, M09

\section{Pain treatment using pain pump}

(BAFA88) (available 1999-)
Surgical procedures involving the shoulder or upper arm

After 1996: [(K)NB]

1.jan1989-31.dec.1995: 7xx00, 7xx01, 7xx02, 7xx03, 7xx04, $7 \mathrm{xx} 05,7 \mathrm{xx} 06,7 \mathrm{xx} 07,7 \mathrm{xx} 08,7 \mathrm{xx} 09$.

Injuries involving the upper arm and shoulder girdle ICD-8: 810-812, 831, 840, 849.00, 849.01, 849.08, 849.09, 880, 887.02, 902.00, 902.01, 902.10, 902.11, 905, 912.99, 923.99, 952.

ICD-10: S40-S49
Clinical Epidemiology

\section{Publish your work in this journal}

Clinical Epidemiology is an international, peer-reviewed, open access journal focusing on disease and drug epidemiology, identification of risk factors and screening procedures to develop optimal preventative initiatives and programs. Specific topics include: diagnosis, prognosis, treatment, screening, prevention, risk factor modification, systematic

Submit your manuscript here: http://www.dovepress.com/clinical-epidemiology-journal

\section{Dovepress}

reviews, risk \& safety of medical interventions, epidemiology \& biostatical methods, evaluation of guidelines, translational medicine, health policies \& economic evaluations. The manuscript management system is completely online and includes a very quick and fair peer-review system, which is all easy to use. 